\title{
Predicting terror
}

Proc. Natl Acad. Sci. USA https://doi.org/10.1073/ pnas.1901975116

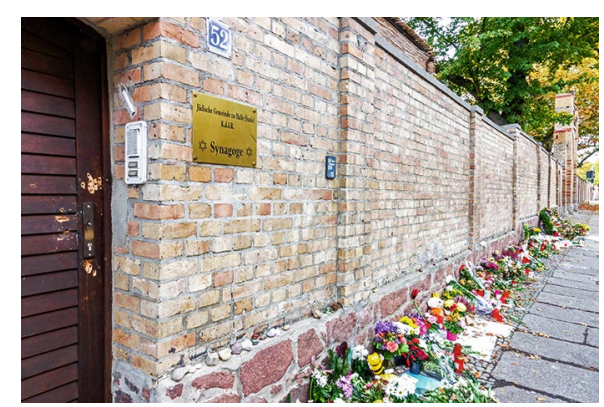

Credit: Cum Okolo / Alamy Stock Photo

Terrorism is increasing at a rate that outstrips counter terrorism resources. Between 2000 and 2015, 61 new terrorist groups have emerged, on average, every year. To prevent terrorist attacks, predicting who will pose the greatest danger is key. But how do we know which groups will persist and maim or kill people?

Yang Yang of Northwestern University and colleagues present a new model that increases our ability to predict which groups will conduct lethal attacks in the future. The model relies on estimating predictors that also determine the success of business organizations: a group's capabilities and resources. The added challenge is that the capabilities and resources of terrorist groups are hidden. Their model estimates capabilities, such as expertise in bomb-making, by measuring the relative lethality of a group's first five attacks, and approximates resources from the time between the first attacks. When attacks are evenly spaced in time, this indicates high resources. Thus, by integrating information about early lethality and the distribution of attacks in time, the model is able to predict how dangerous a terrorist group is likely to become.

The model represents an important area of scientific research, aiming to provide the knowledge that allows security forces to protect civilians.

Anne-Marike Schiffer

Published online: 29 November 2019

https://doi.org/10.1038/s41562-019-0792-2 